\title{
A Comparison of Glomerular Filtration Rate by Creatinine Based Equations and DTPA-Renogram in Healthy Adult Kidney Donors
}

\author{
Ramesh Kumar Chaurasia,, ${ }^{1}$ Rajendra Kumar Agrawal, ${ }^{1}$ Rajani Hada, ${ }^{1}$ Sweta Kumari Chaurasia, ${ }^{2}$ Santosh \\ Gurung, ${ }^{1}$ Shakti Basnet ${ }^{1}$ \\ 'Department of Nephrology, Bir Hospital, ${ }^{2}$ Kanti Children Hospital, Kathmandu, Nepal.
}

ABSTRACT

Introduction: Accurate determination of donor kidney function has important long-term implications for both donor health and recipient outcome. Many centers use 24 hour urinary creatinine clearance or creatinine-based GFR estimations to assess kidney function but their performance when compared with GFR measurements by isotope clearance remains inconclusive. We assessed the performance of creatinine based equations against DTPA GFR for evaluating Nepalese kidney donors.

Methods: All kidney donors who had undergone both DTPA GFR estimation and 24 hour urine $\mathrm{CrCl}$ were included. The performance of the urine- $\mathrm{CrCl}, \mathrm{CG}-\mathrm{CrCl}$, modified MDRD GFR against DTPA GFR was evaluated by analyzing global bias, precision $\left(\mathrm{R}^{2}\right)$,Pearson correlation and accuracy percentage within $30 \%$ and $15 \%$. The sensitivity and specificity of each predictive equation in selecting donor with GFR of $\geq 80 \mathrm{~mL} / \mathrm{min} / 1.73 \mathrm{~m}^{2}$ was also calculated.

Results: Of 51 donors analysed, only 18 (35.29\%) were male. The mean measured GFR was $102.752 \pm 16.71 \mathrm{~mL} / \mathrm{min} / 1.73 \mathrm{~m}^{2}$. Of all prediction equations, urine-CrCL has most precision $\left(\mathrm{R}^{2}=0.207\right)$ with the highest pearson correlation $(0.455)$ and highest accuracy percentage within $30 \%$ and $15 \%$. However, predictive performance was poor for all the equations. The urine $\mathrm{CrCl}$ had highest sensitivity of $100 \%$ for detecting donor with measured GFR> $80 \mathrm{~mL} / \mathrm{min} / 1.73 \mathrm{~m}^{2}$ with positive predictive value of $92.1 \%$.

Conclusions: The performance of all equations was disappointing and even the best performing equation urine- $\mathrm{CrCl}$ was suboptimal for donor selection. So considering the potential risk of living kidney donation, other more accurate methods of GFR estimation should be used.

Keywords: Cockcroft-Gault equation; creatinine clearance; glomerular filtration rate; modification of diet in enal disease formula; ${ }^{99 m}$ Tc-Diethylene-Triamine Pentaacetic Acid.

\section{INTRODUCTION}

Accurate estimation of donor Glomerular Filtration Rate (GFR) is essential both to ensure a donor's medical suitability and to predict future allograft performance as higher GFR of donors is independently associated with improved allograft outcomes. ${ }^{1,2} \mathrm{~A}$ wide approach is used to assess kidney function, with most centers using 24 hour urinary creatinine clearance (urine- $\mathrm{CrCl}$ ) or creatinine-based GFR estimations such as Modification of Diet in Renal Disease (MDRD) or Cockcroft-Gault (CG) equation..$^{3,4}$ However, it has several deficiencies such as errors in collecting urine and tubular secretion of creatinine. ${ }^{5}$ In addition, race is an important determinant of GFR estimation. ${ }^{6}$ The performance of creatinine based estimates of GFR compared with the standard GFR measurements by isotope clearance

Correspondence: Dr. Ramesh Kumar Chaurasia, Department of Nephrology, National Academy of Medical Sciences, Bir Hospital, Kathmandu, Nepal. Email: happyrkc@gmail.com, Phone: 9843099765. 
Chaurasia et al. A Comparison of Glomerular Filtration Rate by Creatinine Based Equations and DTPA-Renogram in Healthy...

remains inconclusive. ${ }^{2}$ There is no comparative study that verifies the performance of creatinine based GFR in Nepalese healthy population. Our aim was to evaluate performance of creatinine based equations against DTPA GFR inkidney donors.

\section{METHODS}

A cross sectional study was conducted in the department of Nephrology, National Academy of Medical Sciences, Bir hospital, Kathmandu, Nepal from June 2011 to Feb 2013. Ethical approval was taken from Institutional Review Board, along with informed verbal consent from all subjects. All patients who came to the department of nephrology for kidney donor evaluation during the study period, with both 24 hour urine $\mathrm{CrCl}$ and ${ }^{99 \mathrm{~m}} \mathrm{Tc}$ Diethylene-Triamine Pentaacetic Acid (DTPA) renogram measurements were included whereas kidney donors without DTPA renogram were excluded.

Data regarding age, gender, place of residence, weight, height, body surface area (BSA), blood urea, serum creatinine and serum albumin for each subject were collected. Rest of investigations was done as per standard protocol for live kidney donor evaluation.

Modified Jaffe's method was used with auto analyzers to measure serum creatinine. ${ }^{7}$ Twenty four hour urine creatinine clearance was determined from a 24 hour urine collection by using formula: 24 hour urine- $\mathrm{CrCl}=\mathrm{UV} / \mathrm{P}$, where $U$ and $P$ are urinary and plasma concentrations of creatinine and $V$ are the urine flow rate. ${ }^{8} A$ creatinine clearance results were normalized to Body Surface Area (BSA) of $1.73 \mathrm{~m}^{2}$; BSA was calculated by Body Surface Area (Mosteller, square root method). BSA $=$ sqr(Height xWeight/3600). ${ }^{9}$ The Cockcroft-Gault equation was used to estimate creatinine clearance from the Serum Creatinine (SCr) as follows. ${ }^{10}$

$$
\begin{gathered}
\mathrm{CrCl}(\mathrm{mL} / \mathrm{min}) \quad=\frac{\text { Age in year) } \times \text { Lean Body Weight }[\mathrm{kg}]}{\text { Creatinine }[\mathrm{mg} / \mathrm{dL}] \times 72} \times 0.85 \text { (if female) }
\end{gathered}
$$

The calculated value was again adjusted for BSA of $1.73 \mathrm{~m}^{2}$

The calculation of the GFR using modified four variables formula, the abbreviated MDRD equation was used as follows. ${ }^{11}$
$\operatorname{GFR}\left(\mathrm{mL} / \mathrm{min}\right.$ per $\left.1.73 \mathrm{~m}^{2}\right)=186.3 \times\left(\mathrm{SCr}^{-1.154}\right)$ X $\left(\mathrm{Age}^{-0.203}\right) \times 0.742$ (if female) x 1.21 (if black)

Measurement of GFR by DTPA renogram (DTPA GFR) was Camera-based, Gates (low dose) method, performed in the nuclear medicine laboratory at Bir Hospital and Magnetic Resonance Imaging (MRI) Centre, Kathmandu. The subjects were orally hydrated with $0.5 \mathrm{~L}$ of fluid for the ${ }^{99 \mathrm{~m}}$ Tc- DTPA renogram study and ${ }^{99 \mathrm{~m}}$ Tc-DTPA dosed at $50 \mathrm{Ci} / \mathrm{kg}$ was injected intravenously. Dynamic images were obtained for 30 min using a dual headed variable angle Gamma camera. The total and individual kidney GFR was calculated using the Gates method and the values were normalized to BSA of $1.73 \mathrm{~m}^{2} .{ }^{12,13}$

All data were analyzed using the statistical program SPSS(PC +) version 20.0. Results were expressed as means $\pm S D$. The student t-test was used for comparison of means. Bias was defined as mean of difference between estimated GFR and measured GFR. The percentage of estimated GFR obtained from each equation falling within $15 \%$ and $30 \%$ of measured GFR were calculated and used as a measure of accuracy of the prediction equation. The precision was measured by $R^{2}$ statistics, which was derived by simple linear regression analysis. Pearson's correlation was used to measure the correlation between estimated GFR and measured GFR. The three prediction equations were compared and ranked for their performance with respect to global bias, precision, correlation and accuracy and final rank for each equation was given after adding up each rank. The best performance in each category was ranked as one and the worst as five. Equal performances for two or more equations were given the same rank. The sensitivity and specificity of each equation in selecting a donor with DTPA-GFR of $\geq 80 \mathrm{~mL} / \mathrm{min} / 1.73 \mathrm{~m}^{2}$ was also calculated, and their relative accuracies were measured by area under Receiver Operating Characteristic $(\mathrm{ROC})$ curves. $\mathrm{P}$ value $<0.05$ was considered as significant.

\section{RESULTS}

There were total 51 cases during the study period. The mean age of kidney donors was $40.84 \pm 2.1$ years with age range of 20 to 65 years and male to female ratio of $0.53: 1$. The mean measured GFR was $102.752 \pm 6.71 \mathrm{~mL} / \mathrm{min} / 1.73 \mathrm{~m}^{2}$ with higher GFR in female than male donor (Table 1 ). 
Chaurasia et al. A Comparison of Glomerular Filtration Rate by Creatinine Based Equations and DTPA-Renogram in Healthy...

\begin{tabular}{|llll|}
\hline \multicolumn{4}{|l|}{ Table 1. The demographic profiles of healthy kidney donors. } \\
\hline Variables & Total $\mathbf{N}=\mathbf{5 1}$ & Male $\mathbf{N}=\mathbf{1 8}$ & Female $\mathbf{N}=\mathbf{3 3}$ \\
Age (years $\pm \mathrm{SD})$ & $40.84 \pm 12.108$ & $42.33 \pm 11.391$ & $40.03 \pm 12.578$ \\
Weight $(\mathrm{kg})$ & $54.02 \pm 9.511$ & $58.89 \pm 8.670$ & $51.36 \pm 8.989$ \\
Height $(\mathrm{cm})$ & $156.63 \pm 11.105$ & $166.78 \pm 8.286$ & $151.09 \pm 8.164$ \\
Body surface area $\left(\mathrm{m}^{2}\right)$ & $1.53 \pm 0.16651$ & $1.6478 \pm 0.14289$ & $1.4658 \pm 0.14287$ \\
Serum creatinine $(\mathrm{mg} / \mathrm{dL})$ & $0.9294 \pm 0.17583$ & $1.0611 \pm 0.15770$ & $0.8576 \pm 0.14149$ \\
Blood urea $(\mathrm{mg} / \mathrm{dL})$ & $42.892 \pm 6.9508$ & $24.889 \pm 6.5340$ & $24.894 \pm 7.2670$ \\
Serum albumin $(\mathrm{gm} / \mathrm{dL})$ & $4.8333 \pm 0.48894$ & $4.8722 \pm 0.45349$ & $4.8121 \pm .51281$ \\
DTPA-GFR $(\mathrm{mL} / \mathrm{min})$ & $102.7520 \pm 16.71871$ & $97.5094 \pm 12.15367$ & $105.6115 \pm 18.28602$ \\
\hline
\end{tabular}

Mean calculated $\mathrm{CrCl}$ or GFR was highest by urine $\mathrm{CrCl}$ followed by $\mathrm{CG} \mathrm{CrCl}$ and MDRD GFR (Table 2).

Table 2. Mean calculated $\mathrm{CrCl}$ or GFR, mean bias, precision $\left(\mathbf{R}^{2}\right)$, correlation and accuracy of various prediction equations.

\begin{tabular}{|c|c|c|c|c|c|c|}
\hline $\begin{array}{l}\text { Estimated GFR } \\
(\mathrm{mL} / \mathrm{min} / 1.73 \\
\left.\mathrm{m}^{2}\right)\end{array}$ & $\begin{array}{l}\text { Mean ( } \pm \text { SD) } \\
\text { GFR/CrCl }\end{array}$ & $\begin{array}{l}\text { Bias } \\
(\text { mean } \pm S E)\end{array}$ & $\begin{array}{l}\text { Precision } \\
\left(\mathbf{R}^{2}\right)\end{array}$ & $\begin{array}{l}\text { Pearson } \\
\text { correlation }\end{array}$ & $\begin{array}{l}\text { Accuracy: } \\
\text { percentage } \\
\text { within } 30 \%\end{array}$ & $\begin{array}{l}\text { Accuracy: } \\
\text { percentage } \\
\text { within } \\
15 \%\end{array}$ \\
\hline Urine $\mathrm{CrCl}$ & $116.5231 \pm 18.31526$ & $13.7712 \pm 2.56737$ & 0.207 & 0.455 & 51 & 29.4 \\
\hline $\mathrm{CG} \mathrm{CrCl}$ & $83.9247 \pm 20.51966$ & $-18.8273 \pm 3.40926$ & 0.025 & 0.157 & 27.5 & 15.7 \\
\hline MDRD GFR & $82.9225 \pm 19.46338$ & $-19.8294 \pm 3.35997$ & 0.016 & 0.127 & 29.4 & 7.8 \\
\hline
\end{tabular}

The percentage of estimated GFR falling within $30 \%$ of measured GFR was $51,27.5$ and 29.4 and within $15 \%$ was 29.4, 15.7 and 46.4 for urine $\mathrm{CrCl}, \mathrm{CG} \mathrm{CrCl}$ and MDRD GFR equations, respectively. Only donor weight was associated significantly $(P$ value $=0.027)$ influencing measured GFR in our study population in regression analysis (Table 3).

\begin{tabular}{|llll|}
\hline \multicolumn{3}{|c|}{ Table 3. Multiple linear regression analysis to identify factors affecting measured GFR in healthy renal donors. } \\
\hline Constant & $\beta$ - coefficient & $P$ value & $95 \%$ confidence interval \\
Age & 126.477 & 0.017 & 24.151 to 228.803 \\
Sex & -0.292 & 0.056 & -0.817 to 0.011 \\
Weight & -0.160 & 0.439 & -19.905 to 8.796 \\
Height & -0.341 & 0.027 & -1.128 to 0.071 \\
Urea & 0.117 & 0.538 & -0.397 to 0.751 \\
Creatinine & -0.200 & 0.181 & -1.193 to 0.233 \\
Albumin & -0.001 & 0.994 & -31.516 to 31.273 \\
\hline
\end{tabular}

24 hour urine $\mathrm{CrCl}$ fared the best cumulative ranking among all the creatinine based equations with respect to global bias, precision, correlation and accuracy (Table 4).

\begin{tabular}{|llllll|}
\hline \multicolumn{4}{l}{$\begin{array}{l}\text { Table } \\
\text { 4. Ranking of performance of various prediction equations with respect to global bias, precision, }\end{array}$} \\
\hline Equations & Bias & Precision & Correlation & Accuracy & Cumulative rank \\
Urine CrCL & 1 & 1 & 1 & 1 & 4 \\
CG CrCL & 2 & 2 & 2 & 2 & 8 \\
MDRD GFR & 3 & 3 & 3 & 3 & 12 \\
\hline
\end{tabular}


Chaurasia et al. A Comparison of Glomerular Filtration Rate by Creatinine Based Equations and DTPA-Renogram in Healthy...

Besides the predictive performance, the ability of an equation to safely exclude potential donors with GFR $<80 \mathrm{~mL} / \mathrm{min} / 1.73 \mathrm{~m}^{2}$ is critical. The area under $\mathrm{ROC}$ curves illustrated that $\mathrm{CG}-\mathrm{CrCl}$ equation had the highest accuracy (among the three equations compared) in correctly identifying cases with GFR $\geq 80 \mathrm{~mL} / \mathrm{min} / 1.73$ $\mathrm{m}^{2}$ (Table 5).

Table 5. Sensitivity and specificity of each equation in selecting a donor with a DTPA GFR $\geq 80 \mathrm{~mL} / \mathrm{min} / 1.73$ $\mathrm{m}^{2}$ and positive and negative predictive values and area under the ROC curve.

\begin{tabular}{llllll|}
\hline Equation & $\begin{array}{l}\text { Sensitivity } \\
(\%)\end{array}$ & $\begin{array}{l}\text { Specificity } \\
(\%)\end{array}$ & $\begin{array}{l}\text { Positive predictive } \\
\text { value (\%) }\end{array}$ & $\begin{array}{l}\text { Negative predictive } \\
\text { value (\%) }\end{array}$ & $\begin{array}{l}\text { Area under ROC } \\
\text { curve }\end{array}$ \\
Urine $\mathrm{CrCl}$ & 100 & 0 & 92.1 & 0 & 0.468 \\
$\mathrm{CG} \mathrm{CrCl}$ & 53.2 & 100 & 100 & 15.4 & 0.883 \\
MDRD GFR & 55.3 & 100 & 100 & 16 & 0.838 \\
\hline
\end{tabular}

Utilization of the CG-CrCl equation to estimate GFR was not very sensitive for selecting a donor with a GFR $\geq 80$ $\mathrm{mL} / \mathrm{min} / 1.73 \mathrm{~m}^{2}$ (sensitivity $53.2 \%$ ), but was sensitive enough to detect a donor with mild renal dysfunction (specificity 100\%). Three donors had GFR $<80 \mathrm{~mL} /$ $\mathrm{min} / 1.73 \mathrm{~m}^{2}$ based on DTPA clearance; but all these patients had urine $\mathrm{CLCr}>80 \mathrm{~mL} / \mathrm{min} / 1.73 \mathrm{~m}^{2}$ and so were chosen for donor nephrectomy. The urine $\mathrm{CrCl}$ had highest sensitivity of $100 \%$ for detecting donor with measured GFR $>80 \mathrm{~mL} / \mathrm{min} / 1.73 \mathrm{~m}^{2}$ but specificity was $0 \%$ with positive predictive value of $92.1 \%$ and accuracy of 0.468 (area under ROC curve) only.

\section{DISCUSSION}

Function of a donor kidney has a significant long-term impact on both the donor health and the allograft function in recipient. GFR is the generally accepted marker for overall renal function and can be precisely measured by using the filtration marker $99^{\mathrm{m}}$ Tc-DTPA. However, the cost and equipment required for DTPA-GFR estimation prevent its widespread use in developing countries. ${ }^{14}$ For example, most kidney transplant centers in Nepal use urine- $\mathrm{CrCl}$ as an index of GFR. However, data from several large clinical trials have shown that urine- $\mathrm{CrCl}$ is inaccurate and lacking in precision as an estimate of GFR and serum creatinine itself is affected by multiple factors other than GFR, such as muscle mass and meat product consumption. ${ }^{15-17}$ Therefore several GFR estimating equations have been developed to estimate GFR based on serum creatinine concentration, age, gender, and body size. The CG equation and MDRD study equation are widely used and recommended by the National Kidney Foundation and American Society of Nephrology for use in clinical practice in patients with chronic kidney disease. ${ }^{18}$ However these formulae are limited by the lack of validation in the full range of GFR and in different ethnic groups and both equations have lower precision in high GFR populations and GFR estimates are less useful in the normal range of GFR. ${ }^{19}$ None of the currently available estimating equations had been validated in Nepalese healthy kidney donors. This is the first study from Nepal to check the validity of these equations in kidney donors.

In our study, mean measured GFR was within normal range but higher in female kidney donor than male counterpart which is contrary to general population and this may be due to most of the female donors were younger. The only factor affecting measured GFR was donor's weight. Two donors were $>60$ years of age with measured GFR $<80 \mathrm{ml} / \mathrm{min} / 1.73 \mathrm{~m}^{2}$ but their urine $\mathrm{CrCl}$ was $>80 \mathrm{ml} / \mathrm{min} / 1.73 \mathrm{~m}^{2}$ without alternative suitable donor so went for donor nephrectomy. Four donors had hypertension stage 1 with reasonably controlled blood pressure with single antihypertensive agent and all were having measured GFR $>80 \mathrm{ml} /$ $\min / 1.73 \mathrm{~m}^{2}$.

Our results showed that urine $\mathrm{CrCl}$ method overestimated GFR with bias of $13.77 \pm 2.56 \mathrm{ml} / \mathrm{min} / 1.73 \mathrm{~m}^{2}$ but both CG $\mathrm{CrCl}$ and MDRD GFR equations underestimated GFR by bias of $-18.82 \pm 3.4$ and $-19.94 \pm 3.35 \mathrm{ml} / \mathrm{min} / 1.73$ $\mathrm{m}^{2}$ respectively. Urine $\mathrm{CrCl}$ was most precise and the least scattered. Thus all equations were more or less biased when compared with the measured GFR. Except urine $\mathrm{CrCl}$, no other equations are advantageous for Nepalese populations as it has highest sensitivity of $100 \%$ for detecting donor with GFR $\geq 80 \mathrm{ml} /$ $\mathrm{min} / 173 \mathrm{~m}^{2}$. We compared various prediction equations with respect to degree of global bias, precision, correlation and accuracy, and ranked them according to their performance. Overall, urine $\mathrm{CrCl}$ fared the best, followed by $\mathrm{CG} \mathrm{CrCl}$ and then MDRD GFR equation. The urine $\mathrm{CrCl}$ method gives higher GFR estimates with accuracy percentage within $30 \%$ and $15 \%$ of measured GFR only 51 and 29.4. Zhao WY et al also found the similar type of result like Urine- $\mathrm{CrCl}$ tended to overestimate GFR, with a bias of $14.2 \mathrm{~mL} / \mathrm{min} / 1.73$ $\mathrm{m}^{2}$ and precision $\left(\mathrm{R}^{2}\right)$ estimate of 0.22 . Urine- $\mathrm{CrCl}$ fell within $30 \%$ and $50 \%$ of the DTPA-GFR in $75.9 \%$ and $89.3 \%$ of the cases respectively. ${ }^{14}$ So even it may not 
Chaurasia et al. A Comparison of Glomerular Filtration Rate by Creatinine Based Equations and DTPA-Renogram in Healthy...

be useful for routine screening of renal function in kidney donors.

In our study, all derived GFR from creatinine, CG CrCl and MDRD GFR formulae underestimated actual kidney function. This is similar to the findings of previous studies that also reported under estimation of MDRD GFR formula by 9 to $29 \mathrm{~mL} / \mathrm{min} / 1.73 \mathrm{~m}^{2}$. 5,20-22 The CG$\mathrm{CrCl}$ equation had the highest accuracy in correctly identifying suitable kidney donor with GFR $\geq 80 \mathrm{~mL}$ / $\min / 1.73 \mathrm{~m}^{2}$ followed by MDRD GFR equation and least for urine $\mathrm{CrCl}$ and had specificity of $100 \%$ that is not selecting donors with impaired GFR. Positive predictive value for selecting donors with normal GFR were $100 \%$ for both $\mathrm{CG} \mathrm{CrCl}$ and DTPA GFR equations and only $92.1 \%$ for urine $\mathrm{CrCL}$ thus showing none of these creatinine based method for estimation of GFR clinically accurate in selecting normal donor in Nepalese populations.

Other studies looking at the performance of these equations in Asian populations have also yielded inconsistent results Zuo et al. reported that the abbreviated MDRD equation performed poorly in a Chinese population with CKD when compared with DTPA GFR estimation. ${ }^{23}$ But Kang et al. found that the CG and MDRD study equations had greater accuracy and precision with measured GFR in healthy Korean populations. ${ }^{24}$ However, both the equations severely underestimated GFR similar to our result. Mahajan et al. reported the MDRD stud yequation is the most precise and accurate, whereas CG-GFR is the least biased in Indian population. ${ }^{25} \mathrm{~A}$ racial difference in renal function of patient populations can explain these discrepancies in different studies. The CG equation was designed to predict $\mathrm{CrCl}$ and not GFR. ${ }^{10} \mathrm{CrCl}$ usually exceeds GFR by $10-15 \%$ because of urinary creatinine that is derived from tubular secretion also. ${ }^{26}$ The MDRD equation was also derived from Caucasians with mild to moderate renal failure. ${ }^{27}$ As both the equations were designed to predict 24-h $\mathrm{CrCl}$ or GFR in Caucasian populations, it is not surprising that it performed poorly when used to estimate GFR in Asian populations. Race is an important determinant of GFR estimation. Urinary Creatinine excretion may be lower in Mongolians than in Caucasians and African Americans because both muscle mass and lesser protein intake. ${ }^{28,29}$ Accurate estimation of GFR in subjects with mild to normal renal function is very difficult, because small changes in serum creatinine may result in a substantial change in calculated GFR. Considering that living kidney donation carries a substantial risk for donors with even mildly renal function, these equations are suboptimal. Thus, every donor should undergo a more accurate GFR measurement, such as insulin, ${ }^{125}$-iothalamate, ${ }^{51} \mathrm{Cr}$ EDTA, and $99^{\mathrm{m} T c}$-DTPA or iohexol clearance. Even though these methods are cumbersome and expensive, but they are worthwhile to know the potential risk of living kidney donation and transplant outcome.

\section{CONCLUSIONS}

The mean measured GFR in healthy adult donors in our study was $102.752 \pm 16.718 \mathrm{~mL} / \mathrm{min} / 1.73 \mathrm{~m}^{2}$. The performance of urine- $\mathrm{CrCl}$ and the other equations is disappointing as urine $\mathrm{CrCl}$ overestimates but $\mathrm{CG} \mathrm{CrCl}$ and MDRD GFR underestimates the true GFR. Urine $\mathrm{CrCl}$ estimation performed better in terms of global bias, precision, correlation and accuracy, when compared with $\mathrm{CG} \mathrm{CrCl}$, MDRD GRF. Their poor ability to identify donors with renal dysfunction makes them unsuitable for clinical use.

\section{ACKNOWLEDGMENTS}

We sincerely acknowledge the contribution from all faculties, DM residents in department of nephrology and our patients and their relatives who dedicated themselves to complete this study.

\section{REFERENCES}

1. Poggio ED, Hila S, Stephany B, Fatica R, Krishnamurthi V, del Bosque $C$, et al. Donor kidney volume and outcomes following live donor kidney transplantation. Am J Transplant. 2006 Mar;6(3):616-24.

2. Issa N, Meyer KH, Arrigain S, Choure G, Fatica RA, Nurko S, et al. Evaluation of creatinine-based estimates of glomerular filtration rate in a large cohort of living kidney donors. Transplantation. 2008 Jul 27;86(2):223-30.

3. Delmonico F; Council of the Transplantation Society. A Report of the Amsterdam Forum on the care of the live kidney donor: Data and Medical Guidelines. Transplantation. 2005 Mar 27;79(6 Suppl):S53-66.
4. Davis CL, Delmonico FL. Living-donor kidney transplantation: a review of the current practices for the live donor. J Am Soc Nephrol. 2005 Jul;16(7):2098-110.

5. Rule AD, Gussak HM, Pond GR, Bergstralh EJ, Stegall MD, Cosio FG, et al. Measured and estimated GFR in healthy potential kidney donors. Am J Kidney Dis. 2004 Jan;43(1):112-9.

6. Goldwasser P, Aboul-Magd A, Maru M. Race and creatinine excretion in chronic renal insufficiency. Am J Kidney Dis. 1997 Jul;30(1):16-22.

7. Israni AK, Lasiske BL. Laboratory assessment of kidney disease: clearance, urinalysis, and kidney biopsy. In: Brenner BM editor. Brenner \& Rector's The Kidney. 8th ed. Philadelphia: Saunders Elsevier; 2008. p. 727-8. 
Chaurasia et al. A Comparison of Glomerular Filtration Rate by Creatinine Based Equations and DTPA-Renogram in Healthy...

8. Clausen H. A simplified clearance method with formula, clearance $=$ Uv/P. Med Monatsschr. 1953 Oct;7(10):656-7.

9. Mosteller RD. Simplified calculation of body-surface area. N Engl J Med. 1987 Oct 22;317(17):1098.

10. Cockcroft DW, Gault MH. Prediction of creatinine clearance from serum creatinine. Nephron. 1976;16(1):31-41.

11. Levey AS, Bosch JP, Lewis JB, Greene T, Rogers N, Roth D. A more accurate method to estimate glomerular filtration rate from serum creatinine: a new prediction equation. Modification of Diet in Renal Disease Study Group. Ann Intern Med. 1999 Mar 16;130(6):461-70.

12. Gates GF. Glomerular filtration rate: estimation from fractional renal accumulation of 99mTc-DTPA (stannous). AJR Am J Roentgenol. 1982 Mar;138(3):565-70.

13. Gates GF. Split renal function testing using Tc-99m DTPA. A rapid technique for determining differential glomerular filtration. Clin Nucl Med. 1983 Sep;8(9):400-7.

14. Zhao WY, Zeng L, Zhu YH, Wang LM, Zhou MS, Han S, et al. A comparison of prediction equations for estimating glomerular filtration rate in Chinese potential living kidney donors. Clin Transplant. 2009 Aug-Sep;23(4):469-75.

15. Toto RD, Kirk KA, Coresh J, Jones C, Appel L, Wright J, et al. Evaluation of serum creatinine for estimating glomerular filtration rate in African Americans with hypertensive nephrosclerosis: results from the African-American Study of Kidney Disease and Hypertension (AASK) Pilot Study. J Am Soc Nephrol. 1997 Feb;8(2):279-87.

16. Coresh J, Toto RD, Kirk KA, Whelton PK, Massry S, Jones $\mathrm{C}$, et al. Creatinine clearance as a measure of GFR in screenees for the African-American Study of Kidney Disease and Hypertension pilot study. Am J Kidney Dis. 1998 Jul;32(1):32-42.

17. Bertolatus JA, Goddard L. Evaluation of renal function in potential living kidney donors. Transplantation. 2001 Jan 27;71(2):256-60.

18. 18.National Kidney Foundation. K/DOQI clinical practice guidelines for chronic kidney disease: evaluation, classification, and stratification. Am J Kidney Dis. 2002 Feb;39(2 Suppl 1):S1-266.

19. Coresh J, Stevens LA. Kidney function estimating equations: where do we stand? Curr Opin Nephrol Hypertens. 2006 May;15(3):276-84.
20. Hallan S, Asberg A, Lindberg M, Johnsen H. Validation of the Modification of Diet in Renal Disease formula for estimating GFR with special emphasis on calibration of the serum creatinine assay. Am J Kidney Dis. 2004 Jul;44(1):84-93.

21. Lin J, Knight EL, Hogan ML, Singh AK. A comparison of prediction equations for estimating glomerular filtration rate in adults without kidney disease. J Am Soc Nephrol. 2003 Oct;14(10):2573-80.

22. Poggio ED, Wang X, Greene T, Van Lente F, Hall PM Performance of the modification of diet in renal disease and Cockcroft-Gault equations in the estimation of GFR in health and in chronic kidney disease. J Am Soc Nephrol. 2005 Feb;16(2):459-66.

23. Zuo L, Ma YC, Zhou YH, Wang M, Xu GB, Wang HY. Application of GFR-estimating equations in Chinese patients with chronic kidney disease. Am J Kidney Dis. 2005 Mar;45(3):463-72.

24. Kang YS, Han KH, Han SY, Kim HK, Cha DR. Characteristics of population with normal serum creatinine impaired renal function and: the validation of a MDRD formula in a healthy general population. Clin Nephrol. 2005 Apr;63(4):258-66.

25. Mahajan S, Mukhiya GK, Singh R, Tiwari SC, Kalra V, Bhowmik DM, et al. Assessing glomerular filtration rate in healthy Indian adults: a comparison of various prediction equations. J Nephrol. 2005 May-Jun;18(3):257-61.

26. Shemesh O, Golbetz H, Kriss JP, Myers BD. Limitations of creatinine as a filtration marker in glomerulopathic patients. Kidney Int. 1985 Nov;28(5):830-8.

27. Levey AS, Bosch JP, Lewis JB, Greene T, Rogers N, Roth D. A more accurate method to estimate glomerular filtration rate from serum creatinine: a new prediction equation. Modification of Diet in Renal Disease Study Group. Ann Intern Med. 1999 Mar 16;130(6):461-70.

28. Lee RC, Wang Z, Heo M, Ross R, Janssen I, Heymsfield SB. Total-body skeletal muscle mass: development and cross-validation of anthropometric prediction models. Am J Clin Nutr. 2000 Sep;72(3):796-803.

29. Imai E, Horio M, Nitta K, Yamagata K, Iseki K, Hara S, et al. Estimation of glomerular filtration rate by the MDRD study equation modified for Japanese patients with chronic kidney disease. Clin Exp Nephrol. 2007 Mar;11(1):41-50. 